\title{
Dilemma and Solution of Green Transportation Construction under the Background of Urban Development
}

\author{
Yaoyao Yuan, Xuan Mo, Ya Xiao, Dongxing Xia, Xiaodan Zhao, Zhenwei You* \\ School of Digital Media and Design Arts, Beijing University of Posts and Telecommunications, Beijing, China \\ Email: ${ }^{\star} 1478305799 @ q q . c o m$
}

How to cite this paper: Yuan, Y.Y., Mo, X., Xiao, Y., Xia, D.X., Zhao, X.D. and You, Z.W. (2020) Dilemma and Solution of Green Transportation Construction under the Background of Urban Development. Journal of Transportation Technologies, 10, 244-250. https://doi.org/10.4236/jtts.2020.103015

Received: June 3, 2020

Accepted: June 15, 2020

Published: June 18, 2020

Copyright (C) 2020 by author(s) and Scientific Research Publishing Inc. This work is licensed under the Creative Commons Attribution International License (CC BY 4.0).

http://creativecommons.org/licenses/by/4.0/

\section{(c) (i) Open Access}

\begin{abstract}
With the development of the city and the increase of the population, the demand for transportation is increasing. The increases in transportation ways and demand have also brought certain energy and environmental problems to transportation construction. A good transportation environment and green travel experience have an important role in promoting the happiness of urban life and the sustainable development of society. Based on this, the following solutions are proposed for the construction and development of urban green transportation. First, as a guiding role, the government should formulate active transportation and green transportation policies to promote the reform of multiple public transportation methods. Second, as a leading role, the market can support a variety of the construction of green travel modes, which could encourage the development of shared bicycles and new energy vehicles. Third, as the main role of city, the citizens would like to choose green travel tools with the guidance in the conscious level. If we built green behavior into a fashionable business card of the city, green behavior will lead the city's transportation construction and development.
\end{abstract}

\section{Keywords}

Urban Transportation, Green Travel, Sustainable Development

\section{Introduction}

General Secretary Xi Jinping said in the report of the $19^{\text {th }}$ Party Congress that China would step up efforts to establish a legal and policy framework that promotes green production and consumption, and promote a sound economic structure that facilitates green, low-carbon, and circular development. China will create 
a market-based system for green technology innovation, develop green finance, and spur the development of energy-saving and environmental protection industries as well as clean production and clean energy industries. China encourages simple, moderate, green, and low-carbon ways of life, and oppose extravagance and excessive consumption. To build a good urban development environment and achieve green transportation and green travel, we need to actively carry out green actions such as saving-oriented organs, green families, green schools, green communities and green travel.

At the same time, Beijing's urban traffic is also facing a series of development problems. With the expansion of the city and the development of social economy, the construction of transportation system tends to be huge and complex. At the same time as the separation of Beijing residents' jobs and residences, the way of road travel has changed, the distance of traffic travel has increased and the time has been extended. Transportation becomes scalable and a large number of private cars are on the rise. The problems of time and space concentration are becoming more and more prominent, and a large number of motor vehicle commuters cause congestion and traffic congestion during peak periods of urban traffic. It is the core demand of the construction and sustainable development of social civilization to construct the green travel service system and advocate the concept of green travel.

In the context of advocating green travel and improving traffic conditions, the author will comb through a series of problems encountered in green traffic construction, and make suggestions from the perspective of the government, private enterprises and citizens.

\section{The Importance of Promoting Green Mobility}

Now Green environmental protection has become one of the themes of society. Green travel can directly and effectively achieve energy saving and emission reduction, and help to build a good and sustainable urban production and living environment. In 2016, China signed the "Paris Agreement" in Paris, stipulating that " $\mathrm{CO}_{2}$ emissions peaked around 2030 and peaked as soon as possible", and " $\mathrm{CO}_{2}$ emissions per unit of GDP decreased by $60 \%$ to $65 \%$ compared with 2005 " and other autonomous action indicators [1]. As Beijing's capital, political center and cultural center city, it is imperative to promote green travel.

\section{1) Improve the urban travel environment}

In the economically developed Beijing, as the urbanization process continues to accelerate, the demand for transportation is increasing, and the traffic is dense and congested. Especially during peak hours when commuting to get off work, pollution emissions from vehicles and other vehicles (carbon monoxide, carbon dioxide, hydrocarbons, fine particles, etc.) directly affect the air quality. Promoting green travel requires that when traveling, urban residents prefer public transportation, bicycles, and walking. Propaganda and promotion of green travel can help coordinate the pollution of the transportation system that uses motor vehicles as one of the main means of transportation. In addition to improving air 
quality, green travel also helps reduce urban noise and reduce traffic accidents.

2) Improve the quality of urban life

Compared with private motor vehicles, public transportation has a larger capacity, and under the same conditions of people flowing, the parking space required is smaller. Large-capacity public transportation can effectively provide high accessibility, and residents can quickly get from place A to place B, without having to find a parking location, and get off immediately. Choosing to travel by car and having green driving habits when not necessary will help enhance the social responsibility experience and improve the overall quality of life in the city.

\section{3) Improve residents' health}

The key to constructing a modern urban green transportation service system is to make green travel a fashionable business card. Travelers of different social classes can access green travel methods without barriers, psychological burdens and voluntary choices [2]. The characteristics of the green travel mode are low carbon, no pollution, zero emissions, and low noise. Green travel can reduce a series of air pollution and noise pollution caused by travel, and reduce the impact on human health. In short-distance travel, the use of bicycles, walking and other travel methods can exercise and help improve health.

\section{The Dilemma Faced by Green Transportation Construction}

With the promotion and work of green cities and green travel, the concept of green travel has gradually been accepted by most people, and has achieved certain results in transportation travel. However, the construction and development of green transportation still face certain difficulties due to the unclear objective development laws of transportation construction, the demand for transportation travel, and the unclear awareness of green travel among some urban residents.

\section{1) Road congestion often occurs}

With the development of the urban economy and the increase in people's demand for transportation, road congestion problems have gradually emerged and become one of the main construction problems in the development and construction of transportation. In 2018, Beijing's urban passenger traffic (740420) decreased significantly from 2017, a year-on-year decrease of $2.0 \%$, and a decrease of $38.8 \%$ from 2012 [2] [3]. At the same time, the number of private motor vehicle owners has increased significantly in 2011, but after a slowdown in growth, the growth rate in 2018 was $2.9 \%$. In Beijing cars travel more frequently on weekdays and morning and evening peaks, which puts certain pressure on transportation. At present, the government has taken some measures to alleviate the traffic jam problem. As a relatively mild policy, the number limit has eased traffic congestion to some extent. In addition, the construction of P\&R (Parking \& Ride) parking lot has reduced the flow of private cars from the suburbs to the central city and eased the traffic pressure in the central city [4]. However, due to various factors such as input cost, capital recovery, and data analysis, the location of the P\&R parking lot cannot meet or excessively meet the needs of the set 
area.

\section{2) Unsatisfactory traffic experience}

According to data from the Beijing Institute of Transportation Development, with the availability of new energy vehicles, by the end of 2018, the number of new energy vehicles in Beijing has increased by $35.6 \%$ compared with 2017. Private travel needs, social wealth and status symbols, and wedding traditions all affect the purchase and use of cars. With the advocacy of energy saving and emission reduction, the emergence of new energy vehicles provides car buyers with more and more environmentally friendly choices. For private cars, travel jams and parking difficulties are the two major travel problems that cannot be avoided. Having a comfortable riding experience, you must face frustrating and even crazy traffic. This is undoubtedly the most sighing phenomenon in urban traffic travel.

On public transportation, the ground bus distribution network is relatively dense, which can basically meet the needs of the nearest ride. High delay rate, long waiting time, inaccurate arrival time and location are the main reasons that affect the bus ride experience. The subway is a fully enclosed or semi-enclosed transportation system with dedicated lanes. It is not affected by the ground traffic environment, and can reach the highest speed in a short time, meeting the requirements of residents, especially office workers, for fast travel [5]. After the opening of the QR code ride service, the phenomenon of dense crowding at the gate of the subway has been improved. However, the extremely short social distance and poor air circulation caused by the crowded cars greatly affect the subway ride experience. Data from the Beijing Institute of Transportation Development show that many subway lines have extremely low comfort indexes during the morning and peak hours. At the same time, the construction of the subway is difficult, so it is self-evident that the distribution of office workers who pursue time and efficiency tends to choose the subway.

\section{3) Traffic planning has a long way to go}

Rail transit has a very strong passenger capacity, accounting for $49 \%$ of the city's passenger traffic in 2018. During Beijing's morning and evening rush hour, rail transit dominates, accounting for $42.6 \%$ and $35.4 \%$ of the total traffic between the morning and evening peaks, respectively. Rail transit has a strong advantage of long-distance travel, but this also indirectly promotes the emergence of the objective phenomenon of "subway crowding". Throughout the construction and development of rail transit in many cities of the world, all have encountered the phenomenon of crowded nodes and the imbalance between supply and demand of line carriers. As shown in the operation and management game "mini subway", the rapid development of the city, complex subway network, increasingly crowded traffic, the need for traffic planners on the city functional areas, construction materials, line characteristics, such as thoughtful consideration, diversified construction strategy.

\section{Green Transportation Construction and Development Suggestions}

Transportation construction is inseparable from the government's macro-control, 
and in addition to complex transportation planning, the potential of the market role is huge. Under the guidance of the market and the guidance of the government, urban residents, as the main elements of green transportation, conduct green travel in terms of conscious behavior, which can better achieve green transportation.

\section{1) Give play to the role of government guidance}

In 2018, the "Beijing Action Plan for Relieving Traffic Congestion" pointed out that "relieving traffic congestion and building a new pattern of transportation development that is guided by public transportation and green behavior" Improving the efficiency of urban traffic operation and ensuring the smooth operation of traffic is also the most important part of green transportation [6]. Priority is given to the development of public transportation and public transportation is regarded as the main method of urban transportation, reflecting the government's practice of the concept of green transportation. In the construction of public transportation, pay attention to the layout of passenger flow lines, improve the management level, realize "zero distance transfer" and "seamless transfer", reduce transportation costs, strengthen network construction, and improve the level of transportation integration [7].

The government encourages and guides the development and construction of the sharing economy industry and green travel reward platform, which can enable the orderly development of the market and promote the market to serve green transportation. In Beijing, the promotion and use of shared bicycles and shared electric vehicles can serve people's short-distance travel and long-distance travel at the beginning and end, while also enabling the concept of green travel to affect people's unconscious systems in a subtle way [8]. The impact on people's unconscious systems helps to cultivate the habit of green travel, enabling urban residents to choose green travel methods more actively.

\section{2) Give play to the leading role of the market}

With the development of economy, the negative impact of production and life on the environment has attracted wide attention. The production model of "high energy consumption", "high consumption" and "high pollution" has gradually changed to a green, rational and controllable mode. Green travel concepts and initiatives have received unprecedented attention, and a large number of travel methods or mobile applications with the theme or main characteristics of environmental protection have emerged in the market. Such as sharing bicycles, walking and planting trees. Shared bicycles and shared electric vehicles can meet the needs of short-distance travel, make up for the shortcomings of limited coverage of subway and bus stations, and regulate traffic flow. The green travel reward platform "green traveler" released by the Beijing Environment Exchange provides users with the service of "parking at home, the longer they are out of service, the more money they make", and directly converts the environmental benefits of parking at home into visible money. This model can strengthen the link between the two concepts of "reducing private car travel" and "benefiting society and itself", foster good travel habits, and gradually improve residents' green 
travel awareness. Diversifying the ways of green travel and giving it a variety of status and taste symbols such as fashion, fashion, and identity all contribute to the practice of environmental awareness.

\section{3) Give full play to the role of citizens}

Although reducing the number of motor vehicle licenses, actively promoting the use of new energy vehicles, and implementing motor vehicle number limit travel, many policies have been implemented, but the growth rate of total motor vehicles is still around $2.5 \%$, and the use of private car users is also constantly increase. The problems of traffic users in Beijing and the environmental problems caused by traffic are becoming more and more serious. Compared to policies, regulations and energy technologies, changes in citizens' travel behavior and increased environmental awareness are more important. Only by weakening the demand for private cars, reducing the frequency of use, and achieving green travel for urban residents can the problem be fundamentally solved [5]. Low-carbon transportation and green travel are inevitable choices for urban transportation development. Under the influence of the government's publicity and market preferential policies, urban residents' awareness of green travel is also increasing. However, there is still a long distance between the consciousness of green travel and the actual realization of green travel. In actual life, the choice of transportation tools will be affected by many factors, such as destination distance, traffic conditions, congestion, ease of adoption, social status, and face. How to increase the awareness of green travel among urban residents and increase the frequency of green travel behavior are very critical issues. As residents' awareness of green travel increases, residents' understanding and acceptance of restrictive policies such as restricting the use of private cars in the city center will increase, and they are more willing to choose public transportation, bicycles and other travel. For citizens who have car purchase needs, their tendency to purchase new energy vehicles will also increase.

\section{Conclusions}

In view of Beijing's increasingly severe form of transportation construction, this article analyzes and discusses the parties involved in construction development from the difficulties faced by transportation construction, and puts forward suggestions for the realization of green travel. The main recommendations are: 1) rational allocation of transportation resources, improvement of public transportation ride experience, improvement of P\&R parking lot quantity and quality, dredging of traffic, improvement of road congestion; 2) encouragement of the market to develop shared bicycle and shared electric vehicle platforms The integration of green travel and environmental protection transportation concepts in the construction of spiritual civilization; 3) Through various channels to enhance residents' travel awareness and give full play to the main role of urban residents.

Smooth roads and clean environment are the core requirements for green travel. Increasing the efficiency of residents' transportation trips can effectively reduce the cost of social operations; enhancing the transportation trip experience also 
helps residents to be more willing and proactive in choosing green transportation modes. In public transportation, rationally planning the transfer distance between subways and designing a reasonable transfer time can effectively alleviate the congestion caused by the large passenger flow at the transfer station. At the same time, improving the services of ground buses and raising the level of information services will help the overall realization of green travel.

\section{Acknowledgements}

This paper is supported by the Projects supported by the Beijing Social Science Foundation Grant No. 17YTB022.

\section{Conflicts of Interest}

The authors declare no conflicts of interest regarding the publication of this paper.

\section{References}

[1] Huo, J., Weng, Y.Y. and Zhang, X.L. (2016) Path Analysis of China's Low-Carbon Energy Economic Transition in 2050. Environmental Protection, 16, 38-42.

[2] Liu, H.D., Chen, X.M. and Li, Z.Y. (2018) Research on Promoting Urban Green Travel in My Country under the New Development Concept. Journal of the Management Cadre College of the Ministry of Transport, 28, 12-16.

[3] Beijing Transport Institute (2019) Beijing Transportation Development Research Institute. http://www.bjtrc.org.cn/List/index/cid/7.hml

[4] Chen, P.H. and Shi, M.X. (2019) Analysis of Influencing Factors of Parking and Transfer Behavior in Beijing. Journal of Beijing Jiaotong University, 18, 38-46.

[5] Wang, Y.Y. (2014) Research on Feature Extraction Method of Public Transportation Commuting Trip Based on Multi-Source Data. Beijing University of Technology, Beijing.

[6] Kong, L.B. and Li, Z.Y. (2019) Traffic Congestion Management and Public Transport Priority at the Stage of Stock Development. Urban Transport, 17, 5-10.

[7] Li, Z.Q., Ou, G.L. and Mao, G.Y. (2016) Research on Spatial Correlation between Highway Transportation Infrastructure and Regional Economic Development. Journal of Yunnan University of Finance and Economics, 32, 50-61.

[8] Sternberg, E. (2018) The Logic of Nerve. Guangxi Normal University Press, Guilin. 